NATIONAL LABORATORY MANAGED BY UT-BATTELLE FOR THE DEPARTMENT OF ENERGY

\section{INDUSTRIAL USE OF DISTRIBUTED GENERATION IN REAL-TIME ENERGY AND ANCILLARY SERVICE MARKETS}

September 2001

\author{
C. R. Hudson \\ B. J. Kirby \\ J. D. Kueck \\ R. H. Staunton
}

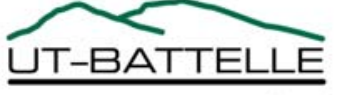


This report has been reproduced from the best available copy.

Reports are available to the public from the following source:

National Technical Information Service

5285 Port Royal Road

Springfield, VA 22161

Telephone: 703-605-6000 (1-800-553-6847)

TDD: 703-487-4639

Fax: 703-605-6900

E-mail: orders@ntis.fedworld.gov

Web site: http://www.ntis.gov/ordering.htm

Reports are available to U.S. Department of Energy (DOE) employees, DOE contractors, Energy Technology Data Exchange (ETDE) representatives, and International Nuclear Information System (INIS) representatives from the following source:

Office of Scientific and Technical Information

P.O. Box 62

Oak Ridge, TN 37831

Telephone: 865-576-8401

Fax: 865-576-5728

E-mail: reports@adonis.osti.gov

Web site: http://www.osti.gov/products/sources.html

Reports produced after January 1, 1996, are generally available via the DOE Information Bridge:

Web site: http://www.doe.gov/bridge

This report was prepared as an account of work sponsored by an agency of the United States government. Neither the United States government nor any agency thereof, nor any of their employees, makes any warranty, express or implied, or assumes any legal liability or responsibility for the accuracy, completeness, or usefulness of any information, apparatus, product, or process disclosed, or represents that its use would not infringe privately owned rights. Reference herein to any specific commercial product, process, or service by trade name, trademark, manufacturer, or otherwise, does not necessarily constitute or imply its endorsement, recommendation, or favoring by the United States government or any agency thereof. The views and opinions of authors expressed herein do not necessarily state or reflect those of the United States government or any agency thereof. 

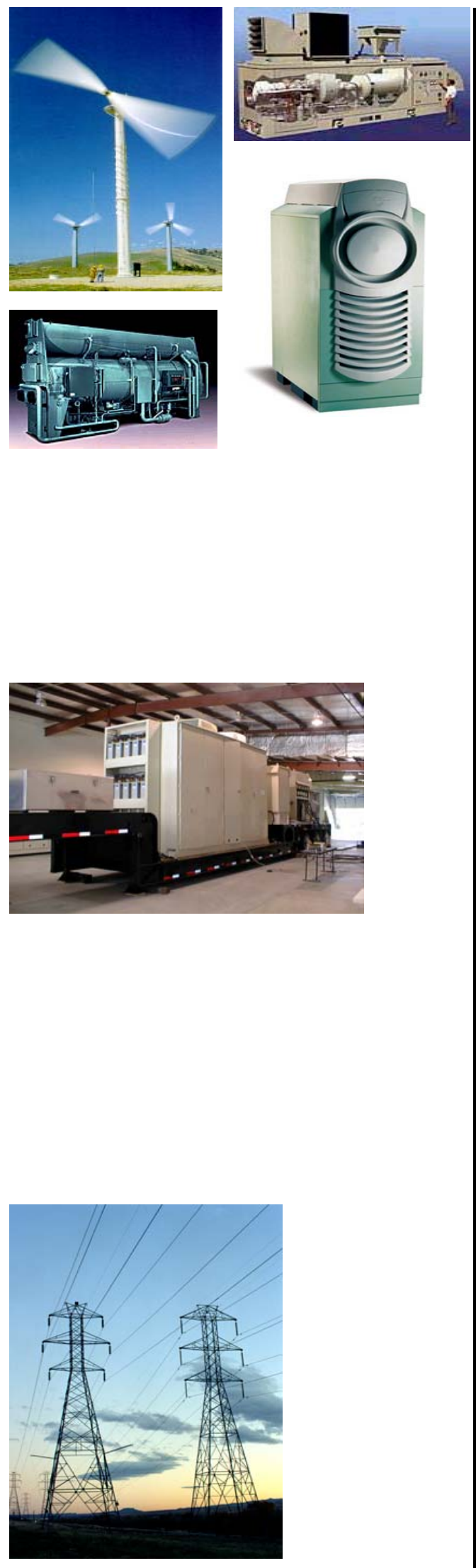

C. R. Hudson

B. J. Kirby

J. D. Kueck

R. H. Staunton

September 2001

\author{
R. H. Staunton
}

INDUSTRIAL USE OF DISTRIBUTED ANCILLARY SERVICE MARKETS

Prepared by

OAK RIDGE NATIONAL LABORATORY

P.O. Box 2008

Oak Ridge, Tennessee 37831-6285

managed by

UT-Battelle, LLC for the

U.S. DEPARTMENT OF ENERGY

under contract DE-AC05-00OR22725 


\section{CONTENTS}

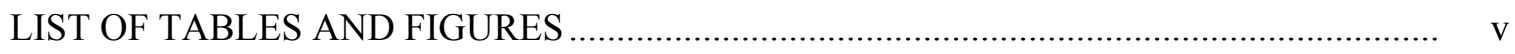

ABBREVIATIONS AND ACRONYMS …............................................................. vii

1. RESTRUCTURING AND EVOLVING MARKETS: AN INTRODUCTION ........................ 1

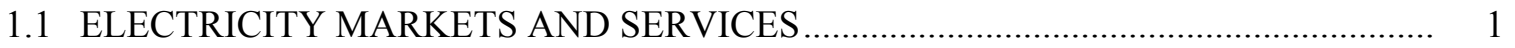

1.2 CURRENT BARRIERS TO DISTRIBUTED GENERATION ...................................... 3

2. TECHNICAL REQUIREMENTS FOR DISTRIBUTED GENERATION ............................ 5

2.1 RESPONSE TIME REQUIREMENTS FOR GENERATION SERVICES ….................. 5

2.1.1 Voltage Support through Reactive Power Supply ............................................. 6

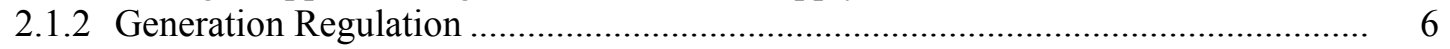

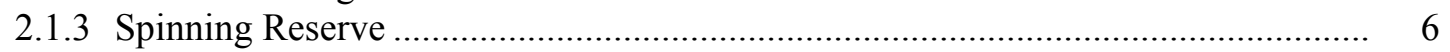

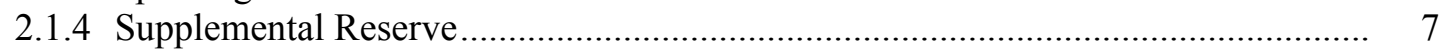

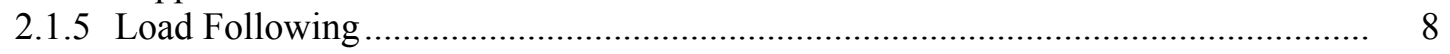

2.1.6 System Black Start ................................................................................... 8

2.1 .7 Energy Market Power ….............................................................................. 8

2.2 GENERATOR RESPONSE REQUIREMENTS ……................................................ 9

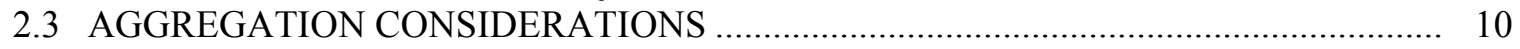

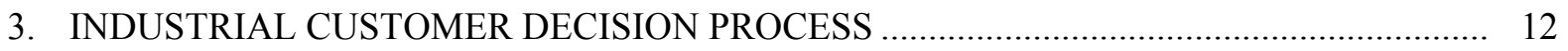

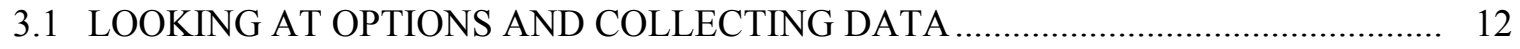

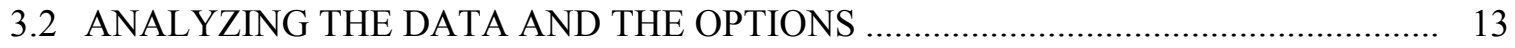

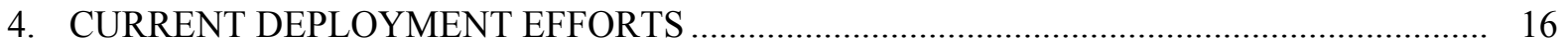

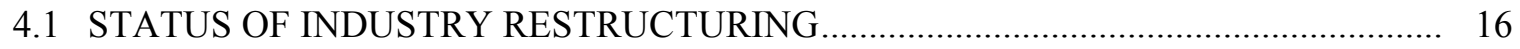

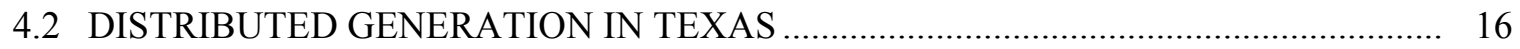

4.3 DISTRIBUTED GENERATION ON THE DELMARVA PENINSULA …....................... 17

4.4 OTHER DISTRIBUTED GENERATION ACTIVITIES ............................................. 18

4.4.1 PJM Pilot Load Reduction Program ............................................................. 18

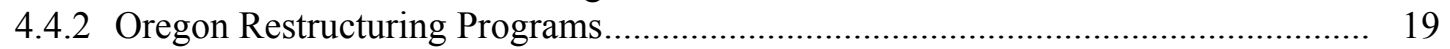

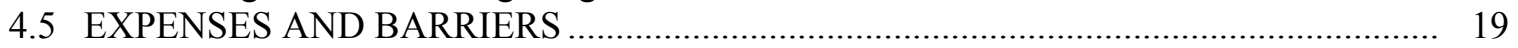

5. COMMUNICATION TECHNOLOGIES............................................................................ 22

5.1 TECHNOLOGIES FOR NEAR-TERM COMMUNICATION NEEDS ........................... 22

5.2 BROAD-SCOPE COMMUNICATION TECHNOLOGIES .......................................... 23

5.2.1 Software-Based, Multi-Device Systems …......................................................... 23

5.2.2 Advanced Infrastructure for Monitoring and Control......................................... 24

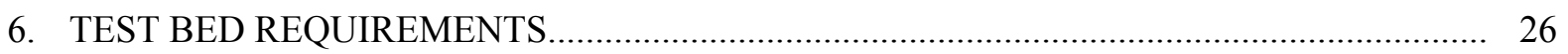

6.1 TESTING RELATED TO END-USE CONCERNS................................................ 26

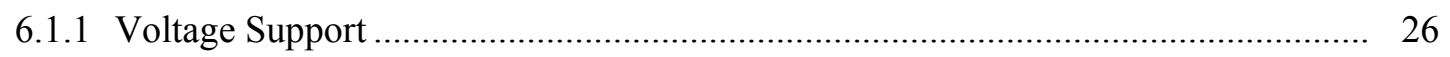

6.1.2 Other End-Use Power Quality Concerns: Harmonics, Imbalance,

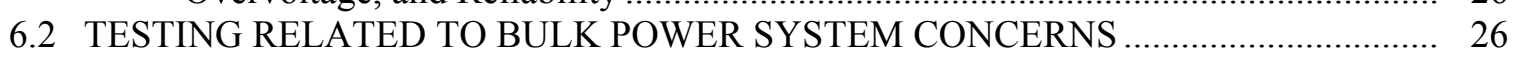

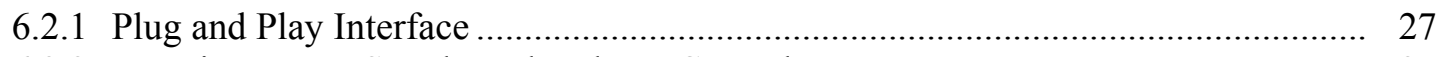

6.2.2 Reactive Power Supply and Voltage Control..................................................... 27 


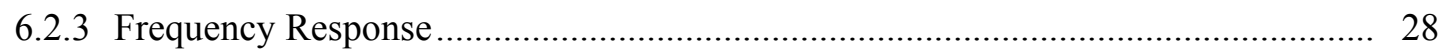

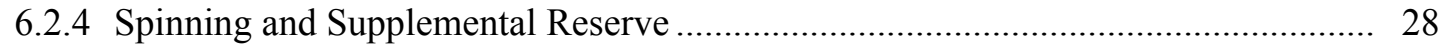

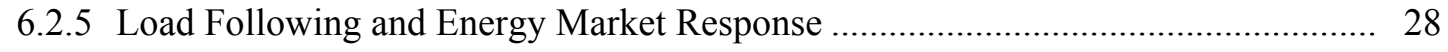

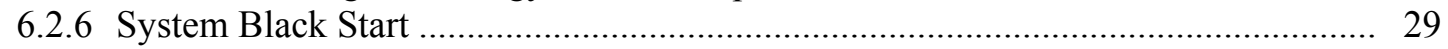

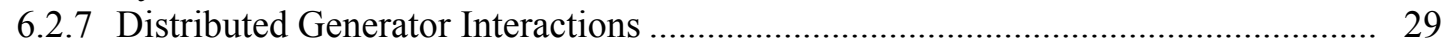

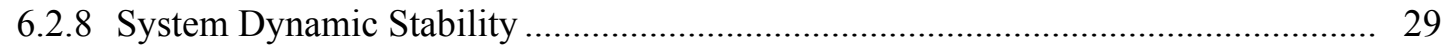

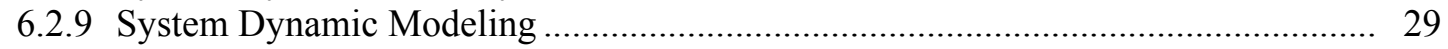

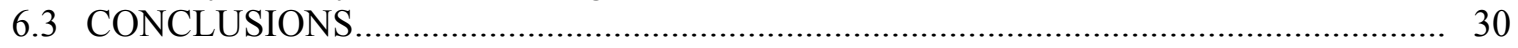

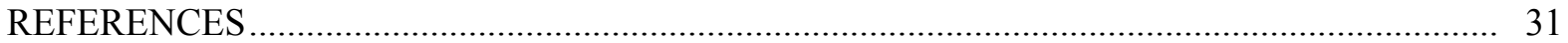




\section{TABLES AND FIGURES}

Tables

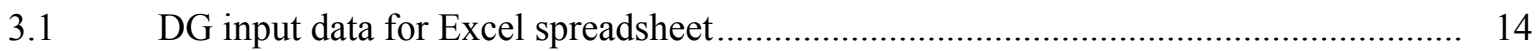

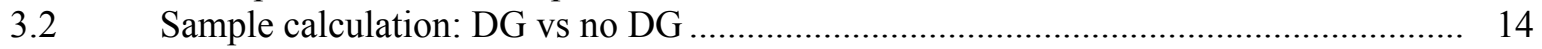

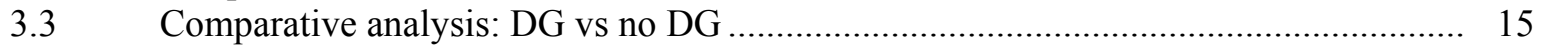

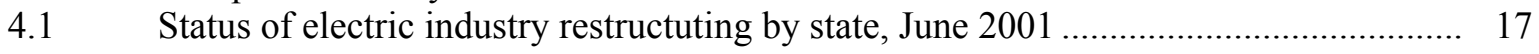

4.2 Summary of reporting electric utilities in Texas, March 2001 .................................. 17

Figures

2.1 Hypothetical frequency-to-generator output relationship ..................................... 10

3.1 Recommended DG operating schedule on basis of spreadsheet calculations ............... 15 


\section{ABBREVIATIONS AND ACRONYMS}

$\begin{array}{ll}\text { AMR } & \text { automated meter reading } \\ \text { CECA } & \text { Comprehensive Electricity Competition Act } \\ \text { CPM } & \text { communication processor module } \\ \text { DCS } & \begin{array}{l}\text { Disturbance Control Standard } \\ \text { distributed energy resources } \\ \text { distributed generation }\end{array} \\ \text { DER } & \text { U.S. Department of Energy } \\ \text { DG } & \text { dispatch work station } \\ \text { DOE } & \text { emergency management system } \\ \text { DWS } & \text { Electric Reliability Council of Texas } \\ \text { EMS } & \text { Federal Energy Regulatory Commission } \\ \text { ERCOT } & \text { Institute of Electrical and Electronics Engineers } \\ \text { FERC } & \text { independent system operator } \\ \text { IEEE } & \text { maximum emergency generation } \\ \text { ISO } & \text { micro-electro-mechanical systems } \\ \text { MEG } & \text { multilevel converter } \\ \text { MEMS } & \text { Mean time to failure } \\ \text { MLC } & \text { North American Electricity Reliability Council } \\ \text { MTTF } & \text { National Renewable Energy Laboratory } \\ \text { NERC } & \text { operations and maintenance } \\ \text { NREL } & \text { programmable logic controller } \\ \text { O\&M } & \text { Public Utility Regulations Policy Act of 1978 } \\ \text { PLC } & \text { supervisory control and data acquisition } \\ \text { PURPA } & \text { volt-ampere reactive } \\ \text { SCADA } & \text { Western Systems Coordinating Council } \\ \text { var } & \\ \text { WSCC } & \end{array}$




\section{RESTRUCTURING AND EVOLVING MARKETS: AN INTRODUCTION}

$\mathrm{J}$ ust as the airlines and telephone companies have undergone major restructuring in previous years, the electricity utility industry is experiencing a paradigm shift not seen since the beginning of commerce in electricity production. In the early days of the electric power market, independent generators and distributors competed with each other for customers, turning streets into a jungle of power lines. The confusion and inefficiency of multiple suppliers gave way to a more orderly arrangement with the consolidation of providers in the 1920s. Legislation dating back to the New Deal created a uniquely structured market for electric power. The concept governing this structure was the "regulatory compact," in which regulators gave investor-owned electric utilities a territorial monopoly on service in exchange for the obligation to provide service to all customers in that territory.

However, increasing energy prices in the 1970s fueled the desire for additional market competition. The non-utility "qualifying facility" provisions of the Public Utility Regulatory Policies Act of 1978 augmented competitive forces in the electric industry. The Energy Policy Act of 1992 gave the Federal Energy Regulatory Commission (FERC) clear authority to order transmission access, a necessary condition for effective supply competition. In 1996, FERC issued Order 888, which opened transmission access to non-utilities, thereby establishing wholesale competition, and Order 889, which required utilities to establish electronic systems to share information about available transmission capacity. At the same time, state legislators and regulators in several states have extended FERC's functional unbundling of transmission and distribution from generation and have introduced retail competition. While the "wires" function will remain regulated, the generation of electricity has essentially been opened to any interested party.

Because of this policy shift, industrial consumers of energy now have the opportunity to participate directly in electricity generation. This report seeks to give the reader (1) insights into the various types of generation services that distributed generation (DG) units could provide, (2) a mechanism to evaluate the economics of using DG, (3) an overview of the status of DG deployment in selected states, and (4) a summary of the communication technologies involved with DG and what testing activities are needed to encourage industrial application of DG. Section 1 provides details on electricity markets and the types of services that can be offered. Subsequent sections in the report address the technical requirements for participating in such markets, the economic decision process that an industrial energy user should go through in evaluating distributed generation, the status of current deployment efforts, and the requirements for test-bed or field demonstration projects.

\subsection{ELECTRICITY MARKETS AND SERVICES}

Industrial consumers of electricity are likely to be familiar only with the end product of the electric utility industry - that is, the incoming electricity and its capacity to do work through various conversion devices. Historically, industrial customers have paid for electricity consumption through a state-regulated tariff structure, in which industrial customers are charged for both the amount of energy consumed and for the rate in which the energy is obtained (i.e., energy and power or capacity). In simplified terms, the energy charge can be related to the variable costs of electricity production [e.g., fuel and operations and maintenance (O\&M)], and the capacity charge can be thought of as the 
fixed cost to provide the electricity (e.g., the costs of physical assets such as power plants and distribution substations). In most competitive marketplaces today, electricity is marketed on a perunit-of-energy basis. In this case, fixed production costs (but not fixed distribution costs) are assumed to be captured implicitly in the market-determined price of the electrical energy.

Typically, the competitive energy marketplace is structured as two separate market actions. There is a "day ahead" market in which suppliers offer bids for each hour of the following day. There is also a spot market in which bids are offered for same-day use, with at least an hour's notice of selection. In either case, the supplier offers a specified amount of energy at a given price. The energy marketplace is coordinated by an entity that seeks to match buyers (i.e., loads) and sellers (i.e., generators). That entity may take the form of a power exchange, as in California, and/or an independent system operator (ISO), as is found in many states. The coordination entity selects bids, ordered by ascending bid price, until the energy demand is met. The winning bidders are then notified as to how much power to provide to the grid and when to supply it.

Other elements involved in providing electricity to the end user have historically been handled internally by the vertically integrated utility companies. Such services were "bundled" in the electricity price charged to the end user and were thus transparent to the end-user. With the restructuring of the electricity industry and the introduction of generation supply competition, these services, collectively referred to as "ancillary services," are also being offered in the competitive marketplace.

FERC has defined ancillary services as "those services necessary to support the transmission of electric power from seller to purchaser given the obligations of control areas and transmitting utilities within those control areas to maintain reliable operations of the interconnected transmission system." There are several categories of ancillary service, including voltage support, regulation, operating reserve, and backup supply.

- Voltage support relates to the ancillary service of ensuring that the line voltage is maintained within an acceptable range of its nominal value. Line voltage is strongly influenced by the power factor of the particular line (i.e., the amount of real and reactive power present in a power line). In turn, the power factor can be modified by the provision or removal of reactive power sources. Reactive power can be obtained from several sources, including electric generators or electronic waveform generators (i.e., power electronics).

- Regulation deals with the minute-to-minute imbalances between system load and supply. Generation that provides regulation service must be equipped with automatic control systems capable of adjusting output many times per hour. Because the generation assets that provide regulation must be on-line, providing power to the grid, in order to provide regulation, it is assumed that companies not specifically in the generation business would not desire to participate in the regulation market.

- Operating reserve comes in two categories - spinning and nonspinning. Spinning reserve comes from generating equipment that is on-line and synchronized to the grid, that can begin to increase output immediately, and that can be fully available within 10 minutes. Because of the requirement to be on-line, an industrial customer may or may not be interested in participation in the spinning reserve market. Nonspinning reserve, or supplemental reserve, does not have to be on-line when initially called. 
- Backup supply services and supplemental reserves are very similar in function, differing in response-time requirements. Nonspinning reserve typically is required to fully respond within 10 minutes of the call to perform. The response time requirements for backup supply vary across transmission control areas but are generally in the 30- to 60-minute time frame. Because supplemental reserve and backup supply do not require a generation source to be already on-line when called, industrial customers may be more likely to participate in these two ancillary service markets.

An ancillary service such as supplemental reserve can be effectively provided by either generation sources or loads. A willingness to curtail electricity consumption upon demand constitutes a form of operating reserve in which the load on the system is reduced rather than the supply being increased. The net effect, of course, is the same. When an industrial customer has a dedicated power source in the form of distributed generation, or DG, that customer can reduce or eliminate its load from the grid system while still maintaining facility production. Whether an industrial customer's operation of its DG is considered a reduction in system load or an increase in system supply is, to an extent, semantic. From either viewpoint, the company is participating in the competitive energy and/or ancillary service markets.

The revenue obtained from participating in competitive energy and/or ancillary service markets will vary, depending on many factors, including the season, the time of day, the weather, and the applicable market settlement rule. In most competitive energy markets, every winning (selected) bidder is paid the last accepted bid price (i.e., the marginal price). Thus, unless a bid is equal to or greater than the marginal price, the revenue received will be at a rate greater than the actual price bid. This is termed a uniform price auction and is a commonly used settlement method in the energy market. Settlement rules for ancillary services are more complicated and have considerable variation among control areas. One settlement arrangement for ancillary services is to pay all successful bidders the last accepted bid price for a service plus an opportunity cost payment for the profit forgone in the energy market. (A generator cannot provide both firm energy and ancillary service support simultaneously and therefore must forgo participation in the firm energy market to the extent of its ancillary service bid.)

\subsection{CURRENT BARRIERS TO DISTRIBUTED GENERATION}

The use of DG as a complement to grid-based electricity is still in its infancy. As a result, there are as yet no standardized methods for a DG owner (i.e., an industrial user) to interface with the electricity grid in terms of permitting, operation, and contractual arrangements. A recent study by the National Renewal Energy Laboratory (NREL) reviewed 65 DG projects in order to assess the difficulty in interconnecting to the grid (Alderfer, Eldridge, and Starrs 2000). Of the 65 cases, in only 7 instances were the DG resources completed and interconnected on a satisfactory timeline with no major utilityrelated barriers. The other projects identified a variety of technical, business-practice, and regulatory barriers. Among the findings summarized on pp. 34-35 of the report:

- Lengthy approval processes, project-specific equipment requirements, or high standard fees are particularly severe for smaller DG projects.

- Many barriers occur because utilities have not previously dealt with small-project or customergenerator interconnection requests.

- There is no national consensus on technical standards for connecting equipment, necessary insurance, reasonable charges for activities related to connection, or appropriate charges or payments for DG. 
- Official judicial or regulatory appeals are often seen as too costly for relatively small-scale DG projects.

- Proponents of DG projects frequently felt that existing rules did not give them appropriate credit for the contributions they make to meeting power demand, reducing transmission losses, and improving environmental quality.

The NREL report (p. iv) identifies ten actions that are needed in order to reduce the barriers to DG:

1. adoption of uniform technical standards for interconnecting distributed power to the grid;

2. adoption of testing and certification procedures for interconnection equipment;

3. accelerated development of distributed power control technology and systems;

4. adoption of standard commercial practices for any required utility review of interconnection;

5. establishment of standard business terms for interconnection agreements;

6. development of tools for utilities to assess the value and impact of distributed power at any point on the grid;

7. development of new regulatory principles compatible with distributed power choices in both competitive and utility markets;

8. adoption of regulatory tariffs and utility incentives to fit the new distributed power model;

9. establishment of expedited dispute resolution processes for DG project proposals; and

10. definition of the conditions necessary for a right to interconnect.

The remainder of this report will address many of these needed actions. 


\section{TECHNICAL REQUIREMENTS FOR DISTRIBUTED GENERATION}

\subsection{RESPONSE TIME REQUIREMENTS FOR GENERATION SERVICES}

The communications requirements that have been established for large central generating plants may be overly stringent for small distributed generators, also known as distributed energy resources (DER). The speed of supervisory control and data acquisition (SCADA) signals are now on the order of 2 to 8 seconds. Protective relaying and trip transfer signals are faster, but these are in a separate category from the bid, dispatch, and performance monitoring of DG. Bid, dispatch, and performance monitoring communications need to be accomplished only in the 1- to 2-minute range.

Current North American Electricity Reliability Council (NERC) policies call for reliable and redundant communications networks for "voice, AGC, SCADA, special protection systems, and protective relaying." Historically, utilities have used a range of technologies to fulfill this requirement to observe and control the transmission system and communicate with generators. Microwave, fiber optics, leased telephone lines, owned telephone lines, and power line carrier are in common use.

The amount of information that must be communicated via these networks is quite small. For an ancillary service transaction the information conveyed is typically only the amount of power in megawatts and a price. Likewise, the dispatch signals consist only of a megawatt amount. The performance-monitoring signal consists of voltages, amperages, frequency, and power factor. The information carried by each of these types of signals is smaller than that normally carried on a pager signal (a telephone number and a short text message).

DG communication does not require the fast times that transmission-related communication does because the consequences of a failure to respond are dramatically different. If a large generator supplying $20 \%$ of a control area's reserves does not respond, the control area is in serious trouble. In contrast, the failure of a single distributed generator to respond does not jeopardize the security of the control area even if distributed generators in aggregate are carrying all of the reserves.

Communications requirements for distributed generators can be greatly relaxed without adversely impacting system reliability. Similarly, when DG is applied at the distribution voltage level, communication requirements will be much slower than what is needed for generation at the transmission level.

The information required for an assessment of grid stability, such as low-frequency harmonics in voltage and frequency, would probably not be provided from DG connection points unless they were connected in transmission substations. A future control system concept is for distributed control agents. These agents would be highly intelligent, unmanned control centers scattered throughout the grid. The agents would monitor and analyze local conditions, detect problems such as frequency oscillations and voltage sag, and send control and dispatch signals to local distributed generators to maintain desired voltage and frequency levels.

The following paragraphs discuss the services that may be provided by DER and the response time requirements for each service. 


\subsubsection{Voltage Support through Reactive Power Supply}

Most reactive power supply equipment is located on distribution systems, not on the transmission grid. Reactive power supply is sometimes switched on by time clocks that activate the supply when the feeder load is heavy. Such a system can be used when the feeder load is known and consistent. Some automatic switching controls respond to voltage, causing the reactive power supply to come on when voltage deviates below a preset level. Static volt-ampere reactive (var) compensators and synchronous condensers are controlled through adjustment of their voltage set points. After the setpoint is established, the response is automatic and very rapid (a few cycles). In the case of local automatic control for static capacitors and transformer tap changers, the response time is typically a few minutes. When switching is done by the dispatcher, response time is also just a few minutes.

It is likely that distributed generators would also be controlled by one of these methods. If there were a clutch or eddy current drive between the generator and the driver (a reciprocating engine, a turbine, etc.), the generator could be operated in synchronism with the grid and the engine left in a standstill condition. The generator exciter could then be controlled to supply or absorb reactive power in response to the local voltage. However, small generators used for backup or auxiliary power are often not equipped with exciters that allow control of reactive power output. In these cases, a multilevel converter (MLC) could be used at the output of the generator to supply the reactive power. With an MLC, the generator could be turned off and the MLC used to supply reactive power to the distribution system as controlled by a voltage setpoint. The generator would need to be on, obviously, to supply real power.

Because voltage is a local concern, the distributed generator can control local voltage without requiring high-speed communications with the control area operator. In addition, depending on the design of the distributed generator and its inverter, dynamic voltage support may be available even when the generator is not consuming fuel or producing real power.

\subsubsection{Generation Regulation}

Generation regulation control keeps net generation and load balanced within an acceptable range of error (area control error). Although the automatic generation control systems at most utility control centers send raise and lower pulses to individual generators as frequently as every 2 to 4 seconds, generators do not follow such short-term load fluctuations. Instead, generation typically follows load at 1- to 2-minute intervals (Kirby and Hirst 2000b).

Aggregated blocks of distributed generators capable of generating $10 \mathrm{MW}$ or more could be very effective in handling regulation service, especially if the generators were placed in a load pocket an area where insufficient generation presently exists and where transmission import capability is limited. Response time is generally considered to be in the range of minutes, with a ramp-up rate of perhaps 5\% per minute. This response time and ramp-up rate would easily be within the range of DG. An older, conventional combustion turbine of 30-50 MW may have a ramp-up rate of $10 \mathrm{MW} / \mathrm{min}$, and the new smaller turbines can easily reach rated power in one minute.

\subsubsection{Spinning Reserve}

Spinning reserve has traditionally been provided by unloaded or lightly loaded generating capacity that is synchronized to the grid, that begins to respond or ramp up immediately and is fully available within 10 minutes, and that responds to frequency deviations or to a signal to supply. It is used to correct for generation or load imbalances caused by generation or transmission outages. Spinning reserve is a relatively high-priced service and may be an excellent candidate for DG. This is an 
especially good prospect for types of generation that can be operated in an idle mode or even shut down and then be brought up to full load quickly.

Spinning reserve is intended to respond automatically to deviations in frequency or a signal from the control authority. Some of the new microturbines can be started and ramped up very quickly, in a matter of seconds. If these microturbines were aggregated into meaningful generation blocks of $1 \mathrm{MW}$ or more, they could be ideal sources for spinning reserve. One benefit of using small quickstart generating units is that there is no environmental impact from the units idling on-line.

The NERC draft Control Performance Standard require that generating units with nameplate ratings of $10 \mathrm{MW}$ or greater be equipped with governors for frequency response unless restricted by regulatory mandates. Governors typically provide a 5\% droop characteristic (i.e., a 5\% change in frequency will result in a 100\% change in power output) that automatically responds to changes in frequency. Incremental changes in power output are typically achieved in less than 5 seconds. Smaller distributed generators may be designed to provide rapid, large power changes in response to frequency changes to help preserve system stability. While provision of spinning reserve would be a new concept for DG, it is likely to be put into effect in the future if DG constitutes a significant percentage of the total generation - i.e., when larger DG aggregations are capable of providing a few hundred megawatts of power. Distributed generators can provide this service relatively easily because the control signal (system frequency) is already available at each distributed generator. In the long term, DG may be used with power electronics to dampen and correct frequency oscillations, but even this would be a feature that was programmed into the local controlling agent and not necessarily done by communication from a central control authority.

Spinning reserve is one service that requires rapid communication to dispatch, on the order of 5 to 10 seconds. If a large number of generators were aggregated, a pager or other radio signal could be used to provide the dispatch communication to all of them. Each generator's performance would have to be measured at a speed as fast as the service being provided (seconds), so that delivered services could be paid for. It would not be necessary to communicate those measurements back to the control area operator in real time, however, if common mode failures could be avoided.

\subsubsection{Supplemental Reserve}

Supplemental reserve service is the provision of generating capacity to correct for generation or load imbalances caused by generation and transmission outages that is fully available within 10 minutes. For provision of supplemental reserve power, immediate response is not required, as it is with spinning reserve. NERC recently extended the Disturbance Control Standard (DCS) response time requirement for control areas from 10 to 15 minutes. Control area operators typically still require resource response within 10 minutes and use the extra 5 minutes to recognize the contingency and to call for a response.

Since supplemental reserve service does not have to ramp up immediately, it is an ideal candidate for new rapid-start small generators that can start, warm up, and be up to power in 5 minutes. Distributed generators can easily meet the requirement of dispatching the required power within 10 minutes. The 15-minute time frame also allows adequate time for a communication to dispatch time of 3-4 minutes and performance measurement for service payment of another 3-4 minutes. Communications back to the central control can be slower. 


\subsubsection{Load Following}

Load-following service is quite similar to generation regulation except that it occurs over longer time intervals (hourly rather than at 1- to 2-minute intervals) to meet daily variations in load (Kirby and Hirst 2000b). The load-following patterns of customers are highly correlated with each other, and the load changes are often predictable, with similar daily patterns, because of weather dependence and other factors.

Load following is measured in terms of the real power capacity (in megawatts) required over each hour. Some regions (California and PJM Interconnection, an ISO for the Pennsylvania, Maryland, and New Jersey area) are instituting energy markets that clear in 5- or 10-minute intervals. Allowing markets to respond this quickly may eliminate the need for a specific load-following service. Demand for load following would be reflected in the spot energy market.

Because load-following service is typically dispatched at one-hour intervals, a communication time of 3-4 minutes should surely be adequate. Likewise, performance measurement would not need to be faster than 3-4 minutes, and communication back to central control could be slower.

\subsubsection{System Black Start}

"System black start" refers to the ability of a generating station to start up without assistance from the grid and then to energize the grid to help other units start after a blackout occurs. Some major loads, such as Air Force bases, possess large-scale generation capability (on the order of $10 \mathrm{MW}$ or more) that could be used as black start capability. It is unlikely, however, that small generators will play much of a role in this market. Reactive power on the order of several megavars is needed just to energize a transmission line, and tens of megawatts are typically needed to restart large thermal generators.

System black start service involves a number of special concerns for communication, and system restoration practices differ from utility to utility, complicating the issue (Kirby and Hirst 1999). First of all, utilities are reluctant to use commercial telephone lines or pagers for communication during blackout or emergency conditions because phone lines are often overloaded at such times and pagers may be inoperable because of the blackout or likewise be overloaded. Therefore, under black start conditions, dispatch commands are typically given and confirmed verbally over secure voice links. The normal SCADA system may or may not be available, though black start units are typically required to be connected to the SCADA system.

The only distributed generators that are likely to be used for black start are larger units with capacities in the tens of megawatts that are already designed for blackout service. There are a large number of such units, at hospitals, airports, and other large installations; and they may be good candidates for black start service.

\subsubsection{Energy Market Power}

During times of transmission congestion or local generation shortages, hourly energy market prices have been seen to rise rapidly, and in these cases, DG could be quite profitable for the resource owners. During off-peak hours, the wholesale price of power is usually close to the break-even price for large generators, and distributed generators would realize only nominal revenue except when they are located in geographic areas where generation or transmission adequacy is limited. The smaller units may be aggregated, and in this case the aggregator - the person or entity that serves as a broker of multiple DG units, selling the output to a control authority as a combined block of power/energymay provide generation control. The time requirement for this service is typically on an hourly basis, 
although some market systems are shortening this interval to reduce the number of services that are needed.

\subsection{GENERATOR RESPONSE REQUIREMENTS}

In the course of investigating a number of DG case studies (Alderfer, Eldridge, and Starrs 2000), NREL researchers consulted an anonymous utility and obtained information on some of its concerns about DG. The utility stated that it was concerned with possible "islanding" (i.e., unintended, isolated, independent operation) for installations under $300 \mathrm{~kW}$. This utility wanted assurance that the remote systems would auto-disconnect during periods of instability. For larger systems, especially those $\geq 1 \mathrm{MW}$, the utility expressed a strong interest in monitoring and actually controlling the distributed power source. It wanted the capability of monitoring all facets of the generation and loading as well as the ability to disconnect the generator or change its operating parameters during fluctuations of frequency and voltage in the grid.

Whether the utility's concerns were real or whether they were "protectionist" of its business is less important than the issues those concerns raise for implementation of DG. This section discusses some of the types of voltage and frequency upsets that can occur and what responses are required both by the utility itself and by DER.

With the use of state-of-the-art generator control and interface systems, generator response in distributed systems is not likely to be an important factor in the near term. As the use of DG grows, however, the importance of matching response to need may become an important issue in maintaining stable grid performance.

Turbine governor control systems are designed to increase generator power output in response to frequency drops. The characteristic relationship between power output and frequency is referred to as "speed droop" or "steady state regulation." The speed droop caused by the governor is expressed as a percentage of the frequency change between the no-load and the full-load states of the generator. Typically, the speed droop of operating units will range from 4 to $6 \%$. A $6 \%$ speed droop means that as the frequency drops by $6 \%$, the governor will respond by increasing generator output by $100 \%$. If the speed droop is $4 \%$, the governor will respond in the same manner; hence, in this case, it is attempting to limit speed within a tighter band.

Figure 2.1 illustrates a frequency-to-generator output relationship and shows an initial operating point at $200 \mathrm{MW}$ and $60.0 \mathrm{~Hz}$. In this example, the system frequency suddenly drops to $59.5 \mathrm{~Hz}$, probably as a result of a major generator's tripping off-line. As this happens, the unit output increases to $250 \mathrm{MW}$. This "extra" output is provided to the overall power system to help restore the overall generation-to-load balance and prevent the system from collapsing. The power increases by $50 \mathrm{MW}$ in response to a $0.5-\mathrm{Hz}$ frequency change. In this example, the generator's rated output of $300 \mathrm{MW}$ corresponds to a $3-\mathrm{Hz}$ frequency change. This is a $5 \%$ droop (i.e, $3 \mathrm{~Hz} / 60 \mathrm{~Hz}$ ).

Changing the generator's desired output actually involves changing the "load reference setting" for the reference frequency $(60 \mathrm{~Hz})$ rather than directly changing the generator's output itself. Changing the desired output setpoint is equivalent to lowering or raising the line shown in the figure until the new desired output power coincides with $60 \mathrm{~Hz}$. 


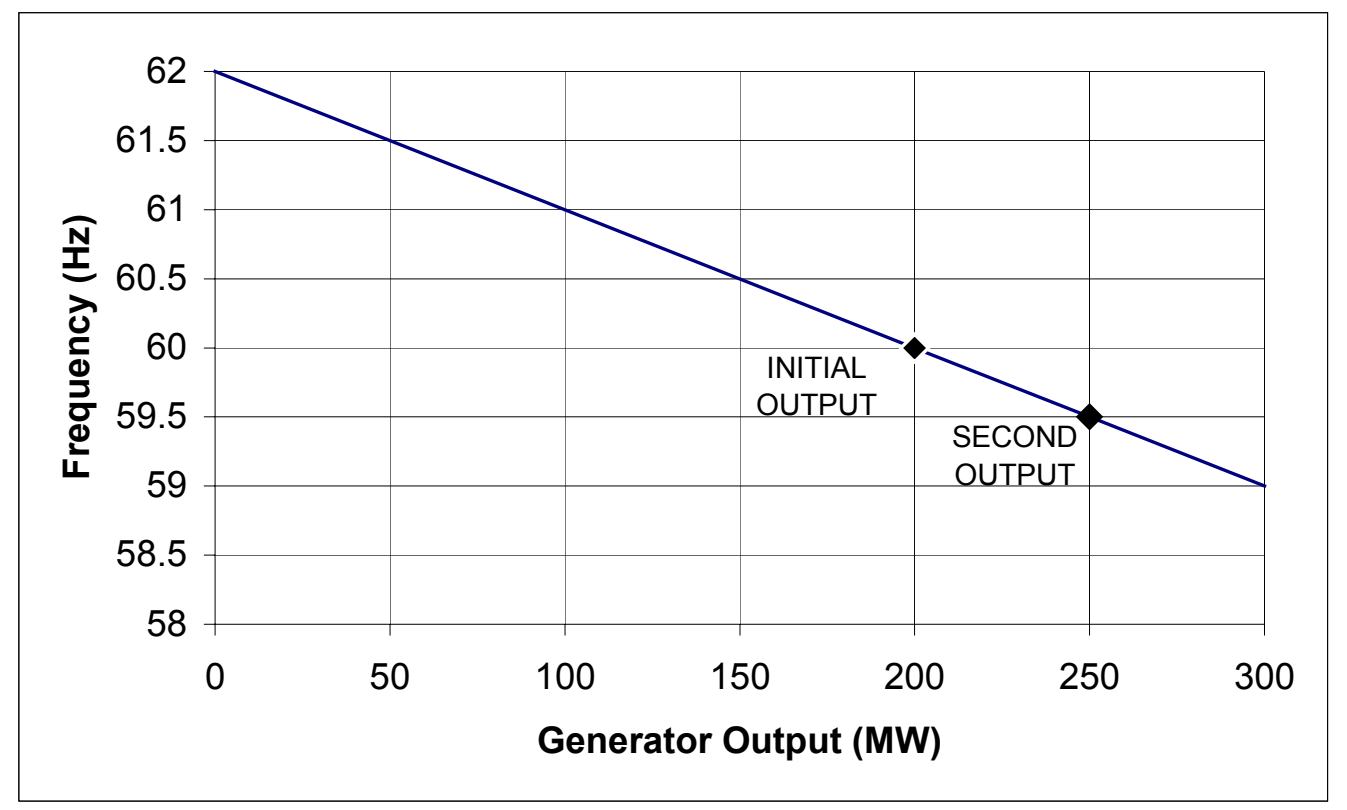

Fig. 2.1. Hypothetical frequency-to-generator output relationship.

\subsection{AGGREGATION CONSIDERATIONS}

From the system planner's point of view, maximum reasonable aggregated generation levels have not become a concern. There is a trend in some areas to aggregate a large number of distributed generators in the form of wind turbines. For example, in west Texas roughly $2500 \mathrm{MW}$ of generation is presently planned from wind farms. Unfortunately, there is little load close by, and the power has to shipped about 700 miles to the Dallas-Fort Worth area over a $345-\mathrm{kV}$ line. A great deal of var support is required in the Dallas-Fort Worth area, but this is too great a distance to ship reactive power. The system modelers and transmission planners think of each aggregated wind farm as a single generator (e.g., a 400-MW wind farm comprising 40 square miles). Power from these wind farms cannot be dispatched in the same way as power from a conventional generator. Instead, wind farms supply power to the grid in response to the available wind.

Power generated by combustion turbines is often a much simpler consideration for system planners than power generated by wind farms. Combustion turbines are typically located closer to loads, and they can deliver their power on demand. The largest aggregation of combustion turbines in the Electric Reliability Council of Texas (ERCOT) transmission system is $1000 \mathrm{MW}$. These can be modeled as one generator for planning purposes. The inertia constants for the DG machines are much smaller, but the big turbine generators still dominate the stability analysis, so there is not yet a stability concern for aggregated DG machines.

Minimum aggregated generation levels are really a concern only for economic reasons. Smaller units could still be dispatched to the grid in large numbers to meet ancillary service and energy market needs as long as connecting them to the grid and controlling them was economically feasible. However, the engineering and relaying costs for small units are sometimes formidable. For example, current ERCOT interconnection requirements for single-phase generators rated $50 \mathrm{~kW}$ and less include an interconnect disconnect device; a generator disconnect device; overvoltage, undervoltage, and over- and under- frequency trips; and a synchronizing check. A three-phase unit over $11 \mathrm{~kW}$ requires all these devices plus a ground overvoltage trip or overcurrent trip and a power directional 
trip. A three-phase unit over $2000 \mathrm{~kW}$ must have all these plus a telemetry/transfer trip and automatic voltage regulation.

ERCOT does provide for precertified generator protection and control units so that once the control and protection package is certified for use by the independent system operator (ISO), the applicant does not have to go through certification again. A standard interface package purchased with the generator can make this interconnection process much simpler and less expensive. Some manufacturers are now providing packaged control systems designed for interconnection.

In the case of small generators, a generation aggregator could provide an important role by interfacing with the control authority. The aggregator could perform several intermediary tasks:

- take the burden of learning the market system from the generator;

- determine what prices individual generators consider acceptable for the various market services and then perform the bidding and market interaction; and

- serve as the recipient of the dispatch signal from the control authority and provide the communication with the individual generator.

The aggregator would handle generators over a certain geographic area. In a densely loaded urban area, the controlled area might be as small as a few city blocks that are fed from one substation. At the other extreme, a west Texas wind farm might cover 40 square miles but be considered one generator from the point of view of the control and planning authority. 
$\mathrm{T}$ The process by which an industrial customer determines whether a distributed resource is of strategic value in its operations is complex and multifaceted. This report assumes that the generation and sale of electricity is not the primary business of the industrial entity but, rather, that the facility uses DG as a complementary adjunct to normal operations. For example, an industrial facility may acquire an emergency generator to provide backup power in the event of a grid outage.

Nevertheless, the recent restructuring of the electric utility industry has created opportunities for industrial customers to participate in the electricity supply marketplace. Whether an industrial facility decides to participate will be heavily influenced by the physical and operational requirements for connecting and interacting with the grid imposed on that customer by the utility system. Another influence will be whether the DG asset is already owned by the industrial entity (e.g., as a backup generator) and is therefore a sunk cost with respect to new electricity market activities. In general, the customer will make that decision on the basis of an economic comparison between staying the course (i.e., doing nothing different) and using DG to participate in electricity supply markets.

This section describes the various elements that go into an economic evaluation of industrial DG. In addition, the section introduces a calculation template that can be used by interested parties to assess the economic viability of participating in the electricity marketplace.

\subsection{LOOKING AT OPTIONS AND COLLECTING DATA}

As discussed in the previous sections, an industrial customer could participate in several markets: the energy market (producing real megawatt-hours of energy), the on-line (spinning) reserve market (selling a reservation of capacity if called upon), and/or the off-line (nonspinning) reserve market. While an industrial entity could engage in other ancillary service markets (e.g., reactive power, regulation, black start), the evaluation process described in this section is confined to the more likely energy and reserve markets.

The evaluation process developed in this study considers the industrial customer's hourly energy demand over a given time period. For each hour within that period, the industrial plant has several options:

- buy energy for the facility from the grid and not offer its DG capacity in any market (the donothing alternative);

- buy energy for the facility from the grid and sell its DG capacity as nonspinning reserve;

- $\quad$ self-generate energy for the facility load and sell any excess DG capacity in the real-time energy market;

- self-generate for the facility load and sell any excess DG capacity in the spinning reserve market; or

- when spinning reserve market prices are relatively high, self-generate at minimum DG output, buy remaining load from the grid (or sell excess generation to the grid), and sell the remaining DG capacity in the spin market. 
While theoretically, the operating mode could change each hour, in practice the various cost parameters that influence a decision generally change temporally in such a way as to produce operation in a given mode for several hours at a time.

In order to determine the mode(s) of operation that would be most economic, the industrial generator needs data on a number of items:

- Load projections - the facility energy demand on an hourly basis

- DG parameters - the capital and operating costs of the DG asset, including the following:

- A variable cost of operation, determined on the basis of DG thermal efficiency (i.e., heat rate), fuel cost, and variable nonfuel operating and maintenance costs (e.g., lubrication oil, operationally driven maintenance and inspection $[\mathrm{O} \& \mathrm{M}]$ )

- Fixed costs, including fixed nonfuel O\&M costs (e.g., staffing) and capital recovery. Capital recovery will be a function of the required or expected rate of return on investment, the duration of economic recovery, and the magnitude of capital investment costs. If the DG asset is already owned by the industrial entity, prior capital investments may be treated as a sunk cost with respect to an electricity market evaluation. However, capital costs related to upgrading the DG or interfacing with the grid should be included in the analysis.

- Expected hourly availability of the DG asset. For example, unit availability may be a factor for facilities operating on less than a 24-hour basis.

- Market price projections - the expected market prices for energy and ancillary services. Because of distribution and transmission charges (i.e., recovery of transmission and distribution asset costs by the regulated wire companies), the price to buy (i.e., consume) electricity will, in a completely competitive market, be higher than the corresponding price to sell electricity into the system. Across the country, there are several variations on energy pricing. In some jurisdictions, the selling of electricity to the grid may be determined by a competitive market while the purchase of electricity by the industrial consumer may be set by a tariff schedule. Ancillary service prices for spinning and nonspinning reserve can be quite volatile and unpredictable. Recent price spikes have brought about price caps in some locations. In addition, settlement rules for setting the price to be paid for a service vary across jurisdictions. An industrial entity evaluating the viability of a DG asset will have to apply the appropriate rules applicable to its location. Fortunately, many ISOs are posting historical prices for services on their web sites. This information can be a useful resource for the difficult task of projecting future market prices.

- Grid system reliability factor - the probability that the grid system will actually call upon a spinning or nonspinning reserve asset to run

\subsection{ANALYZING THE DATA AND THE OPTIONS}

After an industrial facility with DG capability has looked at its generation options and collected cost and other data, it must analyze the data and evaluate its options. To facilitate this process, the authors of this report have developed an Excel spreadsheet that evaluates the operation options identified in Section 3.1 and recommends the lowest-cost option on an hourly basis.

To illustrate this analysis and evaluation process, let us assume that an industrial facility wishes to evaluate the purchase of a distributed generator (e.g., a combustion turbine) for self-generation and participation in the competitive electricity markets. The relevant data for the distributed generator is provided in Table 3.1. The last element in the table, the fixed charge rate (FCR), is the multiplier of total capital cost used to obtain the annual fixed capital allocation related to return of and return on capital investment. 


\begin{tabular}{|l|l|}
\hline \multicolumn{2}{|c|}{$\begin{array}{c}\text { Table 3.1. DG input data for } \\
\text { Excel spreadsheet }\end{array}$} \\
\hline $\begin{array}{l}\text { Capacity, MW net } \\
\text { Capital cost, \$/kW } \\
\text { Variable O\&M, \$/MWh } \\
\text { Fixed O\&M, \$/kW }\end{array}$ & 21 \\
Heat rate, BTU/kWh & 600 \\
$\begin{array}{l}\text { Heat rate at min. } \\
\text { BTU/kWh } \\
\text { Min. output. MW }\end{array}$ & 12000 \\
Fuel cost, \$/MMBTU & 17500 \\
Fixed charge rate (FCR) & 0.2 \\
\hline
\end{tabular}

The results of the hourly computations are shown in Table 3.2 for a sample 24-hour period. The shaded area of the table represents data provided by the user. The megawatt load column (col. 3) shows the industrial facility's energy requirements. In this example, the DG asset is assumed to be available for all 24 hours. The area to the right of the shaded input data provides the results of evaluating the potential operating modes for each hour. Although this example demonstrates the calculations for a single 24-hour period, the spreadsheet model is capable of evaluating up to 7 years of hourly data.

As shown in Table 3.2 and Fig. 3.1, the most economic mode of operation for hours 2 through 9 is to buy electricity from the grid for the facility load, not run the distributed generator, and to offer the DG capacity as nonspinning reserve. During hours 10 and 20, the most economic mode is to sell as much capacity as possible into the spin market. Since the distributed generator must be on-line in order to sell spin, the maximum revenue is achieved by operating the DG at minimum load, buying any additional energy needed for operations from the grid, and selling the greatest amount of DG capacity (i.e., the difference between maximum and minimum DG capacity) in the spin market. During the higher-cost portion of the day (hours 11 through 19), the most economic option is to self-generate the facility demand and sell any excess to the grid via the energy market. The recommended operation in hour 21 is to operate the generator at full capacity and sell into the energy market. Whether the generator is cycled to accomplish this or whether the unit is kept at minimum output as in hours 20,22-24, and 1, the cost impact would be minimal $(\sim 20)$.

The spreadsheet program also produces a summary of the economic results aggregated over the full study period, shown in Table 3.3. In the example, the cost of not using or owning a DG asset and

Table 3.2. Sample calculation: DG vs no DG

\begin{tabular}{|c|c|c|c|c|c|c|c|c|c|c|c|c|c|c|c|}
\hline \multicolumn{16}{|c|}{ Example DG vs. no-DG calculation } \\
\hline & & & & & & & & & & & & & & & \\
\hline & & & \multicolumn{2}{|c|}{ Energy Market } & \multicolumn{2}{|c|}{ A/S Market } & DG & DG & & & Spin & Nspin & Net & No DG & \\
\hline & & MW & \multicolumn{2}{|c|}{ Price, \$/MWh } & \multicolumn{2}{|c|}{ Price, \$/MW } & output & variable & Energy & Energy & A/S & A/S & Cost & Cost & Recommended \\
\hline Date & Hour & Load & Buy & Sell & Spin & Nspin & (MW) & Cost, \$ & Buy, \$ & Sell, \$ & Pymt. & Pymt. & (\$) & $(\$)$ & Unit Response \\
\hline 18-Jul & 1 & 3 & 65.0 & 58.5 & 16.1 & 4.8 & 5.25 & 409 & 0 & 132 & 253 & 0 & 24 & 195 & Gen @ min, sell spin \\
\hline 18-Jul & 2 & 3 & 54.5 & 49.1 & 13.5 & 4.0 & 0 & 0 & 164 & 0 & 0 & 85 & 79 & 164 & Gen @ 0, sell non-spin \\
\hline 18-Jul & 3 & 3 & 50.7 & 45.7 & 12.5 & 3.8 & 0 & 0 & 152 & 0 & 0 & 79 & 73 & 152 & Gen @ 0 , sell non-spin \\
\hline 18-Jul & 4 & 3 & 49.1 & 44.2 & 12.1 & 3.6 & 0 & 0 & 147 & 0 & 0 & 76 & 71 & 147 & Gen @ 0, sell non-spin \\
\hline 18-Jul & 5 & 3 & 50.0 & 45.0 & 12.4 & 3.7 & 0 & 0 & 150 & 0 & 0 & 78 & 72 & 150 & Gen @ 0, sell non-spin \\
\hline 18-Jul & 7 & 9 & 40.5 & 36.4 & 10.0 & 3.0 & 0 & 0 & 364 & 0 & 0 & 63 & 301 & 364 & Gen @ 0, sell non-spin \\
\hline 18-Jul & 8 & 12 & 47.7 & 43.0 & 11.8 & 3.5 & 0 & 0 & 573 & 0 & 0 & 74 & 499 & 573 & Gen @ 0, sell non-spin \\
\hline 18-Jul & 9 & 18 & 49.0 & 44.1 & 12.1 & 3.6 & 0 & 0 & 882 & 0 & 0 & 76 & 806 & 882 & Gen @ 0, sell non-spin \\
\hline 18-Jul & 10 & 19 & 61.0 & 54.9 & 15.1 & 4.5 & 5.25 & 409 & 839 & 0 & 237 & 0 & 1010 & 1159 & Gen @ min, sell spin \\
\hline 18-Jul & 11 & 18 & 74.0 & 66.6 & 18.3 & 5.5 & 21 & 1147 & 0 & 200 & 0 & 0 & 948 & 1332 & Gen @ max, sell excess \\
\hline 18-Jul & 12 & 18 & 84.0 & 75.6 & 20.8 & 6.2 & 21 & 1147 & 0 & 227 & 0 & 0 & 921 & 1512 & Gen @ max, sell excess \\
\hline 18-Jul & 13 & 15 & 88.2 & 79.3 & 21.8 & 6.5 & 21 & 1147 & 0 & 476 & 0 & 0 & 671 & 1322 & Gen @ max, sell excess \\
\hline 18-Jul & $\overline{14}$ & 17 & 105.3 & 94.8 & 26.0 & 7.8 & 21 & 1147 & 0 & 379 & 0 & 0 & 768 & 1790 & Gen @ max, sell excess \\
\hline 18-Jul & 15 & 18 & 115.4 & 103.9 & 28.5 & 8.6 & 21 & 1147 & 0 & 312 & 0 & 0 & 836 & 2078 & Gen@max, sell excess \\
\hline 18-Jul & 17 & 15 & 117.0 & 105.3 & 28.9 & 8.7 & 21 & 1147 & 0 & 632 & 0 & 0 & 516 & 1755 & Gen @ max, sell excess \\
\hline 18-Jul & 18 & 13 & 96.0 & 86.4 & 23.7 & 7.1 & 21 & 1147 & 0 & 691 & 0 & 0 & 456 & 1248 & Gen @ max, sell excess \\
\hline 18-Jul & 19 & 9 & 77.0 & 69.3 & 19.0 & 5.7 & 21 & 1147 & 0 & 832 & 0 & 0 & 316 & 693 & Gen @ max, sell excess \\
\hline 18-Jul & 20 & 6 & 70.0 & 63.0 & 17.3 & 5.2 & 5.25 & 409 & 52 & 0 & 272 & 0 & 189 & 420 & Gen @ min, sell spin \\
\hline 18-Jul & 21 & 4 & 73.8 & 66.4 & 18.2 & 5.5 & 21 & 1147 & 0 & 1129 & 0 & 0 & 18 & 295 & Gen @ max, sell excess \\
\hline 18-Jul & 22 & 3 & 63.0 & 56.7 & 15.6 & 4.7 & 5.25 & 409 & 0 & 128 & 245 & 0 & 36 & 189 & Gen @ min, sell spin \\
\hline 18-Jul & 23 & 3 & 67.0 & 60.3 & 16.6 & 5.0 & 5.25 & 409 & 0 & 136 & 261 & 0 & 12 & 201 & Gen @ min, sell spin \\
\hline 18-Jul & 24 & 3 & 65.0 & 58.5 & 16.1 & 4.8 & 5.25 & 409 & 0 & 132 & 253 & 0 & 24 & 195 & Gen @ min, sell spin \\
\hline TOTAL & & 241 & & & & & 242 & 13927 & 3631 & 5514 & 1522 & 611 & 9911 & 19575 & \\
\hline
\end{tabular}


purchasing all facility electricity from the grid is calculated in Table 3.2, and summarized in Table 3.3, as $\$ 19,575$. If a distributed generator is used, the variable DG cost, purchases and sales of electricity, and ancillary service payments are produce a net variable cost of $\$ 9,911$. Fixed capital and O\&M costs are initially calculated on an annual basis and then prorated to the period under study. Combining variable and fixed DG costs produces a total DG scenario cost of $\$ 17,678$. Compared to the no-DG option, the DG scenario produces a net savings or benefit of $\$ 1,897$ in this example.

The spreadsheet template developed in this task allows for rapid what-if analysis by merely changing the input data. For example, the amount of capital that can be invested in a DG system to produce a break-even total cost between the DG and no-DG cases can be determined by varying the DG capital cost input value shown in Table 3.1. Similarly, tariff structures for the purchase of electricity can be easily introduced in place of market prices in Table 3.2.

\begin{tabular}{|c|c|}
\hline \multicolumn{2}{|c|}{$\begin{array}{l}\text { Table 3.3. Comparative analysis: } \\
\text { DG vs no DG }\end{array}$} \\
\hline Analysis period, hours & 24 \\
\hline Facility energy demand, MWh & 241 \\
\hline \multicolumn{2}{|l|}{ No DG Scenario } \\
\hline Energy cost & $\$ 19,575$ \\
\hline \multicolumn{2}{|l|}{ DG Scenario } \\
\hline DG generation, MWh & 242 \\
\hline DG utilization factor & 0.479 \\
\hline DG variable cost & $+\$ 13,927$ \\
\hline Electricity purchases & $+\$ 3,631$ \\
\hline Less: $\quad$ Electricity sales & $-\$ 5,514$ \\
\hline A/S payments & $-\$ 2,133$ \\
\hline Equals: Net variable cost & $\$ 9,911$ \\
\hline Plus: $\quad$ Prorated fixed cost & $+\$ 7,767$ \\
\hline Equals: Total DG/energy cost & $\$ 17,678$ \\
\hline Net (DG - no DG) cost/benefit, \$ & $\$ 1,897^{a}$ \\
\hline${ }^{a}$ Positive number $=$ DG benefit & \\
\hline
\end{tabular}




\section{CURRENT DEPLOYMENT EFFORTS}

I ndustry has used on-site generation as an important and economical source of electricity for many years, although it has not been called "distributed generation" or "DG." In 1978, a federal law referred to as the Public Utility Regulations Policy Act of 1978 (PURPA) was enacted. One section of PURPA required utilities to purchase electricity from cogenerators, private power suppliers who generated electricity using renewable energy. These new suppliers had to meet certain criteria set by FERC. Many of the suppliers came from the manufacturing sector.

In 1988, manufacturers generated 114.8 billion kWh of electricity on-site. More than half of this electricity (59.1 billion $\mathrm{kWh}$ ) was generated in PURPA-qualifying facilities. In addition, of the 114.8 billion $\mathrm{kWh}$ generated, 83.2 billion $\mathrm{kWh}(72 \%)$ was generated in an establishment interconnected with a utility.

In 1994, manufacturers generated 142.5 billion $\mathrm{kWh}$ of electricity on-site; $90 \%$ of that was cogenerated. Since they generated power in excess of their needs, they sold or transferred 28 million $\mathrm{kWh}$ off-site. Approximately $40 \%$ of all cogenerated electricity was produced within the paper industry. The chemical industry was the next largest cogenerator, having produced $35 \%$. For more information on the historical perspective of DG, the reader may consult Battles (1999).

\subsection{STATUS OF INDUSTRY RESTRUCTURING}

The high level of activity relative to electric industry restructuring in state offices across the country make evident the revolutionary aspect of this movement. States are busy educating consumers and determining what changes are in consumers' best interests. To this end, they are sponsoring numerous studies and investigations that are often led by independent analysts (such as universities). States are also looking at many complex legal issues, soliciting comments on restructuring, holding hearings, writing new bills, issuing orders, and changing existing state laws. Table 4.1 summarizes the status of restructuring in the states as of June 2001. Details on specific activities in some of the more active restructuring states will be provided in the following sections.

\subsection{DISTRIBUTED GENERATION IN TEXAS}

Texas Substantive Rule $\$ 25.211(\mathrm{n})$ requires that each electric utility maintain records concerning applications received for interconnection and parallel operation of DG. The same rule requires that by March 30 of each year, every utility file with the commission a DG report for the preceding calendar year that identifies each DG facility interconnected with the utility's distribution system.

Table 4.2 is a summary of the March 30,2001, informational filings made by all the electric utilities in Texas. It shows the number of DG facilities (those consisting of one or more generator units) and the total electrical power capacity of the DG units at each facility. Other Texas utilities reported no DG. The DG sites vary widely and include banks, hospitals, health care clinics, schools, renewable research projects, and numerous industries (gas utilities, lumber producers, food processors, and producers of bio-energy). 
Table 4.1. Status of electric industry restructuring by state, June 2001

\begin{tabular}{|l|l|}
\hline \multicolumn{1}{|c|}{ Status } & \multicolumn{1}{c|}{ State } \\
\hline $\begin{array}{l}\text { Restructuring legislation } \\
\text { enacted }\end{array}$ & $\begin{array}{l}\text { Arizona, Arkansas, California, Connecticut, Delaware, District of Columbia, } \\
\text { Illinois, Maine, Maryland, Massachusetts, Michigan, Montana, Nevada, New } \\
\text { Hampshire, New Jersey, New Mexico, Ohio, Oklahoma, Oregon, } \\
\text { Pennsylvania, Rhode Island, Texas, Virginia, and West Virginia. }\end{array}$ \\
\hline $\begin{array}{l}\text { Comprehensive regulatory } \\
\text { order issued }\end{array}$ & New York \\
\hline Legislation or orders pending & None \\
\hline $\begin{array}{l}\text { Commission or legislative } \\
\text { investigation ongoing }\end{array}$ & $\begin{array}{l}\text { Alaska, Colorado, Florida, Indiana, Iowa, Kentucky, Louisiana, Minnesota, } \\
\text { Mississippi, Missouri, North Carolina, North Dakota, South Carolina, Utah, } \\
\text { Vermont, Washington, Wisconsin, and Wyoming }\end{array}$ \\
\hline Little or no activity & $\begin{array}{l}\text { Alabama, Georgia, Hawaii, Idaho, Kansas, Nebraska, South Dakota, and } \\
\text { Tennessee }\end{array}$ \\
\hline
\end{tabular}

Table 4.2. Summary of reporting electric utilities in Texas, March 2001

\begin{tabular}{|lcc|}
\hline \multicolumn{1}{|c|}{ Utility } & \multicolumn{1}{|c|}{$\begin{array}{c}\text { No. of } \\
\text { facilities }\end{array}$} & $\begin{array}{c}\text { Capacity of } \\
\text { DG units } \\
\text { (kW) }\end{array}$ \\
\hline $\begin{array}{l}\text { American Electric Power (AEP) } \\
\text { Reliant Energy Heating, Lighting, and Power } \\
\text { (REHLP) }\end{array}$ & 9 & 18,550 \\
Texas Utilities Company (TXU) & 16 & 33,072 \\
$\quad$ All reporting utilities & $\underline{19}$ & $\underline{41,341}$ \\
\hline $\begin{array}{l}\text { Source: Public Utility Commission of Texas, Memorandum from Ed Ethridge, } \\
\text { Electrical Production Engineer, Electric Division, to Commissioners Brett Perlman and } \\
\text { Max Yzaguirre, June 26, 2001: Subject: Open Meeting June 28, 2001; Agenda Item No. } \\
\text { 30 Docket No. 22357-Annual Filing by Electric Utilities. }\end{array}$ \\
\hline
\end{tabular}

\subsection{DISTRIBUTED GENERATION ON THE DELMARVA PENINSULA}

In July 1999, the Delmarva Peninsula - which comprises Delaware, the Eastern Shore of Maryland, and a small area of Virginia - experienced high electrical demand on several occasions that resulted in dangerously low voltage levels on major power lines, forcing the utility to create rolling blackouts in some areas. The areas most affected were in southern Delaware, the Ocean City-Salisbury area, and some Mid-Shore areas of Maryland (Queen Anne's and Caroline Counties). Conectiv Power Delivery, the primary supplier of electricity on the Peninsula, subsequently made a number of conventional improvements. These included a \$11 million upgrade at the Nelson Substation and a similar upgrade at Indian River that include static var compensators for improved voltage control. 
The Office of Power Technologies within the U.S. Department of Energy (DOE) recently commissioned a study to determine the total backup generation capacity on the Delmarva Peninsula. The study (DOE 2000) also investigated what the impact would have been in the summer of 1999 had this generation capacity been fully interconnected, aggregated, and dispatched. The study determined that there is at least 220-240 MW of backup capacity presently installed on the Peninsula. This capacity is equivalent to $10 \%$ of the peak demand that was experienced during the days of highest load in the summer of 1999. According to the study, had this backup capacity been available to supply the grid, it would have significantly improved grid reliability and alleviated the most severe aspects of the 1999 energy shortage.

The study examined the benefits of integrating distributed generators to lower costs and improve reliability. It is thought that the Delmarva Peninsula may represent a convenient laboratory to confirm that DG could be an inexpensive solution to Conectiv's reliability problem. In their present state, the distributed generators represent an underutilized resource. Aggregating and dispatching these DG resources create many advantages not only for the utility, but also for the owners of the backup generators. The aggregator of this resource would be able to sell spinning reserve capacity and peaking energy to PJM Interconnection and, in the process, improve system reliability during peak demand periods.

\subsection{OTHER DISTRIBUTED GENERATION ACTIVITIES}

\subsubsection{PJM Pilot Load Reduction Program}

In an order dated May 17, 2000, FERC issued an announcement (Docket No. EL00-75-000) allowing owners of private generators to sell power to the wholesale market to aid in meeting peak demand during the summer. The PJM pilot program was effective through September 2000. In response, PJM Interconnection, an ISO for the Pennsylvania, Maryland, and New Jersey area, created a pilot program for reducing electric purchases from the utilities. In the program, participants were reimbursed for reducing electric use or relying more on backup generators whenever PJM issued maximum emergency generation (MEG) declarations.

The DG aspect of the program encompassed those PJM member customers who could disconnect from the grid and supply their own electric needs using generators dedicated to their local load. In these cases, there was no need to operate synchronously with the power grid, and no power was exported from the customer's facility.

Participation in the pilot program depended on the customer's ability to

- reduce power within one hour,

- receive the MEG notice from PJM,

- reduce load by at least $100 \mathrm{~kW}$,

- generate for at least 10 hours during the program,

- be available between hours of 9:00 A.M. and 10:00 P.M., and

- meet metering requirements.

The metering equipment produced integrated hourly kilowatt-hour measurements, and customers were reimbursed at the appropriate zonal locational marginal price or $\$ 500 / \mathrm{MWh}$, whichever was higher.

Notification of MEGs was made whenever generation was needed above the maximum economic level or greater than the highest incremental cost. The PJM dispatcher issued the notification and 
ensured that internal management, public information personnel, and local control center dispatchers were aware of it. The dispatcher also requested emergency energy and contacted neighboring control areas. Off-system sales were recalled where possible.

The following functions, key to the process, were performed by the dispatcher:

- declarations of MEG status,

- issuance of requests for load reduction from participants in the pilot program,

- purchase of emergency energy from PJM members, and

- cancellation of load reduction requests.

PJM communicated the load reduction requests through redundant channels: the PJM web site, the Emergency Conditions page, $e$ Data, an All-Call message, and pager notifications.

\subsubsection{Oregon Restructuring Programs}

An important electric restructuring bill, Oregon Senate Bill 1149, was passed and signed into law on July 23, 1999. The bill differs from electric restructuring bills passed by other states in that residential consumers will not have retail access, but will be offered a choice of pricing plans that will be regulated by the Public Utility Commission (Oregonian 1999a,b). With the passage of the bill, fullscale deregulation of the electric industry for non-residential customers is scheduled to begin by October 1, 2001 for qualifying electric companies.

Most business and industrial consumers of qualifying electric companies will be allowed direct access to purchase electricity and certain ancillary services by October 1,2001. Electric companies will unbundle the costs of electricity services into power generation, transmission, distribution, and retail services by this date.

Customers can install their own generation to provide for their own needs. On-site generation is intended to produce savings in total purchased power by reducing delivery costs, delivery losses (i.e., typically about 7\%), and other costs. However, the local utility is permitted to add stand-by or backup charges for customers with their own generation. To these are added charges for specific connection requirements. Thus, how economic customer generation can be in Oregon is the result of several contributing factors.

\subsection{EXPENSES AND BARRIERS}

As noted in Section 1, a recent NREL study examined existing barriers to the interconnection of distributed power generation. The report provided the following summary:

- A variety of technical, business practice, and regulatory barriers discourage interconnection in the U.S. domestic market.

- These barriers sometimes prevent distributed generation projects from being developed.

- The barriers exist for all distributed generation technologies and in all regions of the country.

- Lengthy approval processes, project-specific equipment requirements, or high standard fees are particularly severe for smaller distributed generation projects.

- Many barriers in today's marketplace occur because utilities have not previously dealt with smallproject or customer-generator interconnection requests.

- There is no national consensus on technical standards for connecting equipment, necessary insurance, reasonable charges for activities related to connection, or agreement on appropriate charges or payments for distributed generation. 
- Utilities often have the flexibility to remove or lessen barriers.

- Distributed generation project proponents faced with technical requirements, fees, or other burdensome barriers are often able to get those barriers removed or lessened by protesting to the utility, to the utility's regulatory agency, or to other public agencies. However, this usually requires considerable time, effort, and resources.

- Official judicial or regulatory appeals were often seen as too costly for relatively small-scale distributed generation projects.

- Distributed generation project proponents frequently felt that existing rules did not give them appropriate credit for the contributions they make to meeting power demand, reducing transmission losses, or improving environmental quality. (Alderfer, Eldridge, and Starrs 2000, p. ii)

The NREL study examined 65 DG projects and found in most cases significant barriers to their completion. The most common barriers were existing utility business practices, which is not unexpected for an industry designed for central control of transmission and distribution. Common barriers included contractual and procedural requirements for interconnection. Problems ranged from the unavailability of utility personnel familiar with the issues involved in DG and authorized to act on the behalf of the utility, to time-consuming and arbitrary processes relating to DG.

Regulatory barriers, including tariffs that failed to recognize the economic value of DG to the power system, were also common. Technical barriers, another major category, included requirements for protective relays and transfer switches, power quality, and power flow studies. The study found that some distributed power projects have paid $\$ 600$ to $\$ 40,000$ for interconnection engineering studies.

Such barriers are being challenged on many fronts. One example is the Arthur D. Little, Inc., program called "DG 2000" that brings together energy service providers, equipment manufacturers, regulators, and DOE to pursue DG as a cost-effective energy source. The program creates a forum in which technology, industry, and commercialization experts work with DG participants to exchange information and ideas and to enhance the knowledge base. The program will sponsor workshops with utility regulators and prepare white papers on important issues.

In response to past workshops, DOE has initiated a Distributed Power Program to focus on the issues relating to interconnection of DG to the grid and to address regulatory and institutional barriers. Although nine states have adopted interconnection standards for DG, the variation in standards from state to state will hinder a robust market in distributed power technologies. There is a strong and urgent need to create a nondiscriminatory national standard that applies to all forms of DG and ensures that DG systems are integrated to the grid in a manner that addresses critical safety, reliability, and power quality issues.

The Institute of Electrical and Electronics Engineers (IEEE) is presently developing the standard "Distributed Resources and Electric Power Systems Interconnection" (P-1547). This standard establishes criteria and requirements for the interconnection of distributed resources with electric power grids. The purpose of the standard is to provide a uniform standard for interconnection and provide requirements important to the performance, operation, testing, safety considerations, and maintenance of the interconnection. The development team for the standard has wide industry support from over 270 member companies.

Another significant step forward in the elimination of barriers is the government's Comprehensive Electricity Competition Act (CECA) that was submitted to Congress and enacted on April 15, 1999. This act establishes a uniform national interconnection standard that is enforced by FERC. It requires a distribution utility to allow small-scale distributed power facilities to interconnect if the facilities meet the interconnection standards of the utility. CECA was designed to promote competition in a 
manner that is fair to all parties and provides environmental benefits. As described in a supporting analysis of CECA (DOE 1999), the act

1. encourages states to implement competition at the retail level;

2. promotes competitive markets, enhances information flows, and prohibits customer abuses;

3. assures access to and the reliability of the grid;

4. promotes support for renewable energy and energy efficiency;

5. removes impediments to competition in areas served by the federal power marketing administrations and the Tennessee Valley Authority;

6. protects rural and remote communities and Indian tribes; and

7. provides clarification of federal and state authority. 


\section{COMMUNICATION TECHNOLOGIES}

concern that is often discussed regarding DG, or distributed supply of ancillary services in
general, is the perceived need for the system operator to communicate with numerous private
operators of generators and related services. This section considers conceptual solutions for
both immediate and long-term industry needs; for long-term needs, the discussion assumes that a
mature DG grid will exist and that there will be a large number of individual resources.

Section 2 described, in general terms, the communication functions and technical needs for information coordinators (e.g., aggregators and smart agents) that will be needed to manage intermediary functions. The purpose of this section is to describe technical communications solutions that will meet the needs of the aggregator. The primary criterion is simple: communications at low cost. However, there looms a much greater technical issue — system "control." Therefore, although this section is not intended to address control needs, a comprehensive survey of communications technologies will necessarily encompass some systems with control features.

\subsection{TECHNOLOGIES FOR NEAR-TERM COMMUNICATION NEEDS}

The distributed energy resources (DER) industry, in its current stage of early development, can function satisfactorily with several types of readily available communications technology. NERC policies call for reliable and redundant communications networks for "voice, AGC, SCADA, special protection systems, and protective relaying." Historically, utilities have used a range of technologies to fulfill the requirement to observe and control the transmission system and communicate with generators. Microwave, fiber optics, leased telephone lines, owned telephone lines, and power line carrier are all in common use. All can provide reliable and fast communication for data, control, and voice signals. The draft NERC policy that deals with ancillary service resource providers (Policy 10) calls for "voice and data communications ... to respond to the instructions or controls of the OPERATING AUTHORITY" and for the resource to "provide to the OPERATING AUTHORITY real-time telemetry of the real power output of each IOS RESOURCE." Unfortunately, while traditional utility communications technologies work quite well for large generators, most are too expensive for use with distributed resources.

Apart from control needs, several technologies look appealing for low-cost communication with a large number of distributed resources. Pilot efforts are under way using pagers, the Internet, nondedicated phone lines, and radio (Kirby and Hirst 2000a). In each case the objective is to reduce the per-unit cost of implementation. Communication speed is important but has to be fast in only one direction - from the system to the DER. The fastest signals will generally use a technology that can address a large group of resources with a single deployment command.

Pagers, for example, are promising because they provide individually addressable communications for a $\$ 20$ capital cost and $\$ 5 /$ month per device. The amount of information pagers normally transfer - a telephone number and short text message - is greater than that required for an ancillary service transaction, which typically contains a megawatt amount and a price. Deployment signals contain even less information, a realistic example being simply a megawatt amount. Because pagers are limited to communicating in one direction (from the aggregator to the individual distributed resource), they would not be useful for confirming a generator's acceptance to supply an ancillary 
service for a set time period. ${ }^{1}$ Messages typically get to pagers within about 2 minutes, quite adequate for most ancillary service communications. The pager service provider is constantly assembling batches of messages for broadcast to all pagers. This process results in a slight delay in the communications process. It is possible that the infrequent ancillary service deployment commands for spinning reserve (the ones requiring the greatest speed) could be given higher priority for a higher fee. Prices should drop significantly if a large number of distributed generators participate in this service. And in most cases, the number of participating distributed resources would have to be high in order for DER to meet the business needs of the energy aggregator.

Nondedicated telephone lines can also be used for communications with DER. Devices such as alarm systems and even some advanced electric meters use existing telephone circuits to communicate with central stations. The device accesses the existing phone line, determines if it is currently in use, and makes a phone call to the central station when communications are needed. ${ }^{2}$ This type of technology could be used when a distributed resource needs to communicate a change in availability to the aggregator.

\subsection{BROAD-SCOPE COMMUNICATION TECHNOLOGIES}

A number of new software-based wireless communications systems show promise for fulfilling both the elementary communications needs (at low cost to the dispersed DER service providers) and the higher-level monitoring and control needs in the broader, maturing industry. This section examines a few different communications systems now being marketed and then considers the next higher level of technological innovation, which may offer important advantages in the long term.

\subsubsection{Software-Based, Multi-Device Systems}

Wireless services and networks are designed to receive and transmit packet data (i.e., data bursts). This data-transfer method is the backbone of wireless telemetry. With excess capacity on many paging and wireless carrier networks, telemetry is being further developed to support new applications in the retail, security, and utility industries. Almost all major wireless companies are developing technology for new services, and at least one major company is licensed to cover $95.8 \%$ of the populated area of the United States and much of the populated area of Canada.

Telemetry is now being used in conjunction with many other forms of communications. Wireless companies have bridged the gap between hand-held two-way radios, numeric and alphanumeric pagers, cell phones, and the Internet. For instance, one Windows-based system from Wonderware, called SCADAlarm, provides real-time intelligent alarm notification, data acquisition, and remote control from a multitude of communications devices, including PCs. SCADAlarm will sound alarms over speakers, intercom systems, radios, and telephones or send alphanumeric text messages to pagers and mobile telephones. Operators can move through secure voice menus and listen to alarm details and acknowledge them from any telephone. Additional features that would be useful to information monitoring and control aggregators include the following capabilities: (1) alarms can be grouped and prioritized individually, (2) human voices can be recorded, (3) multiple operator clearance levels are available, (4) extended on-call/backup/courtesy notification groups can be programmed, (5) a text paging terminal allows operators to type/send/message any pager, (6) a global tag spreadsheet provides convenient editing of alarm attributes, and (7) the system continuously monitors and

\footnotetext{
${ }^{1}$ The DG could confirm its agreement by phone, by fax, or via the Internet.

${ }^{2}$ Alarm systems typically seize the phone line to report emergencies. Electric meters typically wait until the phone line is not in use. Some electric meters even sense when another telephone on the premises is picked up and terminate the meter's phone call to avoid interfering with a new outgoing call.
} 
intelligently deploys messages minimizing operator interaction. SCADAlarm is sold in a kit that includes software, a modem, a speaker, and microphone for just under $\$ 2,000$. The software is claimed to be user-friendly and can be mastered in well under an hour.

EnFlex Corporation is another provider of a networked information management monitoring and control system. The EnFlex gateway resides at the remote facility and connects to a variety of intelligent devices. It is designed to send information over TCP/IP networks, the Internet, and more localized intranets (e.g., as a means of delivering aggregated information and energy services). The system connects to the emergency management system (EMS), access control, automated meter reading (AMR) systems, and other intelligent devices from various manufacturers. Using numerous protocols, service providers can consolidate information and deliver services to geographically diverse facilities. A dial-up feature is included for communications with pagers and/or phones. Either the self-contained alarm code can be used or the user may create another using the scripting language. EnFlex is a Linux-based system, and the EnFlex software can be purchased separately (at \$400) or installed in a very compact, rugged computer/controller with six serial ports (typical acquisition costs of $\$ 1300$ to $\$ 2000)$.

On a broader scope, ENCORP, Inc., has developed communications software that is designed to be used in conjunction with that company's line of energy automation products. ENCORP manufactures and packages engine and generator control technologies into integrated control systems. One product, enpower-GPC, is a generator controller that uses LonWorks network communications as one element in a generator/utility package featuring protective relays, harmonics monitoring, energy metering, programmable controller logic, and traditional controls (synchronizer, var/PF control, load sharing).

The two primary communications tools that are used to manage ENCORP's line of switchgear and power controls are the communication processor module (CPM) and the dispatch work station (DWS). These Windows-based, industrial-grade PCs offer various hardware and software communications options. The CPM and DWS provide the platform for local and remote operation and maintenance of the two main ENCORP systems, enpower and encompass. ENCORP also provides a software server, called entelligent, for platform-specific communication with the CPM, and the servers can be customized to meet the application needs of the user. The entelligent automation software is designed to be a simple, user-friendly interface with data logging, alarming, and capacity management scheduling features. A virtual maintenance monitor, referred to as entelligent-VMM, and the virtual power plant software products permit remote dispatch, control, monitoring, and troubleshooting for ENCORP generation products. If desired, systems such as ENCORP's, could provide much more direct control of DER to the aggregator.

\subsubsection{Advanced Infrastructure for Monitoring and Control}

Intelligent agents can be implemented in either wireless or hard-connected microsensor arrays and networks with supporting interfaces. By using inputs from appropriate sensors, these agents can provide the aggregator or microgrid operator with power management capability, communication protocols, archiving capabilities, Internet accessibility, a reconfiguring architecture, computational capabilities, and embedded intelligence. The concept uses a number of emerging technologies, such as wireless telemetry, micro-electro-mechanical systems (MEMS) sensors, embedded intelligence, and complex systems theory. Economy of scale (i.e., hundreds of generators with sensors) will be key to controlling cost.

Intelligent wireless mircosensor arrays integrated into a network of agents and sentinels may become an important technology for fully satisfying the requirements for a DG-based microgrid. One key element in the concept is the use of information agents some of whom may be tied to particular 
sensors (i.e., tethered agents) so that other agents in the network can obtain the needed information from them. Thus, instead of transmitting large amounts of data throughout the network, an agent would go to the data, process it, and obtain only the needed results.

The use of sensors at DER service providers may become desirable in facilitating long-term, unattended operation with high reliability. A remote operator would be able to monitor the state of the system [e.g., input, output, efficiency, mean time to failure (MTTF) estimates] and meter its performance. Longer-term trending data (e.g., vibration, spectra) could be used to assess the health of the equipment and to schedule maintenance. What may seem an elaborate system may be made costeffective through the use of new methods, fabrication, and packaging (e.g., peel-and-stick sensors and other devices that are cheap and disposable). Once the requirement for wires for communications and powering circuits is eliminated, the sensor packaging will become simple and cost-effective. 
$\mathrm{G}$ aining acceptance from system operators and industrial customers for moving DG fully into real-time energy and ancillary service markets will probably require published results from laboratory tests and demonstration projects. Testing requirements can be divided into two broad categories: testing required to address local or end-user concerns and testing required to address bulk power system concerns. Some of this testing is already being done by DG manufacturers, end users, and utilities.

\subsection{TESTING RELATED TO END-USE CONCERNS}

\subsubsection{Voltage Support}

With the nature, configuration, and concentration of today's "electronic loads," there are tremendous opportunities for distributed generators equipped with dc buses and power electronics to improve reliability and provide a site for energy storage methods such as batteries or supercapacitors. The power electronic interface device will then also serve as an uninterruptible power supply and enable the use of dc distribution. Direct current distribution has traditionally been hampered by the high cost of circuit breakers; power electronics can eliminate this barrier by providing reliable circuit isolation and protection as an inherent part of the control module. Tests should be made on a range of voltage sag magnitudes and durations to verify the capability of the power source and interface device to support the voltage supplied to the load.

\subsubsection{Other End-Use Power Quality Concerns: Harmonics, Imbalance, Overvoltage, and Reliability}

DER equipped with power electronic interface devices can correct a host of other power quality problems that shorten equipment lifetime, rob efficiency, and threaten communication and control systems. Conventional power electronic devices, such as computer power supplies and adjustable speed drives, are notorious for creating harmonics that cause overheating and a range of failure modes. Voltage unbalance can cause severe motor overheating and premature failure. Overvoltages are sometimes present when plants are being operated at light load conditions. These problems can be corrected with DER equipped with power electronic devices to condition the power that is supplied to the plant buses. Tests should be made on a range of typical power quality problems to assess the capability of the devices to correct the problems.

The integration of DER into the electrical power system must be seamless with respect to the operations of the end user. Switching and overall power reliability must not have a detrimental effect on facility operations. In fact, demonstration of improved reliability through a seamless transition between resources (i.e., grid vs DER) will be a cornerstone for end-user acceptance.

\subsection{TESTING RELATED TO BULK POWER SYSTEM CONCERNS}

The technical requirements for the participation of DER in energy and ancillary service markets were provided in Section 2. Testing is required to verify that distributed generators in general, and specific distributed generators in particular, can meet these technical requirements and provide valuable services to the electric power system. Testing must verify three separate characteristics: (1) the ability of the distributed generators themselves to respond as required; (2) the ability of the communications 
scheme to transmit market and deployment signals to the distributed generators and to transmit performance verification signals back to the power system operator; and (3) the ability of the aggregation scheme to integrate the response capabilities of numerous individual distributed generators into a single dispatchable resource.

The fact that distributed generators are valuable to the power system only when their response is aggregated is both a drawback and a benefit when establishing testing procedures. The drawback is that full physical verification of the aggregated benefit requires large-scale testing of many DER simultaneously. The benefit is less obvious but just as real: because the aggregated response of numerous distributed generators is required to obtain significant benefits for the bulk power system, the incorrect operation of a single distributed generator will do little harm for many services.

Consequently, some testing can be performed without as great a concern that the security of the power system will be jeopardized if the distributed generator does not perform as expected. (Note that we are not addressing safety issues here: safety must never be jeopardized.) A distributed generator's ability to supply spinning reserve or frequency response could be tested, for example, without the same concern about jeopardizing power system security by poor generator response that would be present while testing a 1000-MW coal-fired generator. Similarly, testing costs are much lower with distributed generators than with large central generators, making it possible to perform much more extensive testing.

It is also possible to segregate the testing of communications and control, aggregation, and generator physical response. While integrated testing will eventually be desirable, it would also be valuable to test the subsystems independently. The segregated testing also has the benefit that testing communications or aggregation schemes without having distributed generators physically respond does not raise the system security concerns that full-response testing might raise.

\subsubsection{Plug and Play Interface}

Power electronics can provide a standard "plug and play" interface between DER and the grid. This interface will provide frequency and voltage conversion, as well as energy storage and protection. This interface must be tested under a range of specified service conditions for voltage, frequency, imbalance, faults, overload, etc., to verify its performance. Ideally, the set of test specifications should encompass a national set of conditions. The regional requirements now being developed could be combined with national consensus standards and other needs to develop a test specification for a truly "standard" interface.

\subsubsection{Reactive Power Supply and Voltage Control}

The ability of the distributed generator to deliver reactive power to the power system will have to be verified over the full range of voltages expected under normal and contingency conditions. Verification related to reactive power delivery involves testing of the following capabilities:

- Reactive output capabilities will need to be tested under the full range of real-power output.

- Reactive support and voltage control from inverter-based distributed generators that intend to provide these services under conditions when no real power is being generated must be tested.

- The distributed generator's ability to control voltage by adjusting its own reactive power output will have to be tested by forcing the bus voltage up and down and observing the generator's reactive power response.

- The dynamic response capability will have to be tested to measure response times. 
- Communications capabilities that adjust the voltage control setpoint will have to be tested. Typically the response time on changing voltage control setpoints is not rapid, so this testing should be relatively easy to perform.

\subsubsection{Frequency Response}

Like voltage control, frequency response is a local response to a locally measured power system condition (in this case, system frequency). It is more difficult to test grid-connected DG frequency response than voltage control because it is difficult to change the frequency of the local bus to which the distributed generator is connected. Physical response testing will be more difficult. Communications testing, on the other hand, is not required. Generator droop characteristics are not adjusted other than during periodic testing. There is no need for the system operator to communicate frequency setpoint or droop characteristic information to the generator. ${ }^{3}$

\subsubsection{Spinning and Supplemental Reserve}

Testing of the distributed generator's ability to supply spinning or supplemental reserve will require measuring the generator's output in response to a deployment command. Real power measurements will have to be taken at least once per second. The amount of time required for the generator to deliver the requested reserve from its pre-deployment power level must be measured. Any overshoot or undershoot over the deployment period (10-30 minutes) must be measured as well. The only difference in testing spinning and supplemental reserves is in the performance assessment, not in the measurements themselves.

Testing communications and aggregation systems will require measuring the speed with which the deployment command can be moved from the power system operator to the individual generator that is to respond. For spinning reserve, the required communications response time will be on the order of seconds. The response time for supplemental reserves communications can be a minute or longer, depending on how fast the generator can respond and the amount of warning it needs in order to have full response available within 10 minutes of the system operator's initial request.

The generator response must be measured locally to the tolerance specified for the service typically a second for spinning reserve and possibly several seconds for supplemental reserve. This will require verifying that both the deployment command and the generator's response are recorded. Communicating the results back to the power system operator must also be verified, though the required response times should not be as stringent.

\subsubsection{Load Following and Energy Market Response}

Verifying the distributed generator's ability to respond to load-following requirements or to participate in real-time or hourly energy markets requires similar testing, though communications and response speeds differ. In all cases, it will be necessary to verify that the distributed generator can respond to commands to adjust its real-power output and maintain that response until directed to readjust it.

The communication system's ability to deliver a real-power setpoint or a price signal must be verified. Load-following signals must move from the system operator to the generators in less than a

\footnotetext{
${ }^{3}$ If the distributed generator were to participate in time correction then it would be necessary to reset the $60 \mathrm{~Hz}$ operating point " $0.02 \mathrm{~Hz}$ in response to interconnection time correction commands, but this type of operation is not expected.
} 
couple of minutes. Energy market signals can take significantly longer. In both cases, it is the system's ability to deliver the signal accurately and the time delay that must be tested.

\subsubsection{System Black Start}

Testing a distributed generator's ability to supply system black start requires that the generator be tested under both islanded and grid-connected conditions. Testing must confirm the following capabilities for the generating unit:

- the unit's ability to start itself without external power,

- its ability to remain stable and control frequency and voltage while the real and reactive loads are changed, and

- its ability to share load with a few other generators.

Communications testing for black start resources is primarily aimed at verifying that the communications system remains viable without support from the local power system or from other utilities.

\subsubsection{Distributed Generator Interactions}

It is also necessary to test how multiple distributed generators interact when they are placed electrically near each other on the power system (e.g., several units on the same distribution feeder). Testing of multiple distributed generators of the same type will be required, as will testing of the interactions between different types of distributed generators. Interactions are possible not only when active control is being exercised, but also when the distributed generators are operating independently and simply trying to supply base-load energy. Combinations of units in both conditions will have to be tested.

The characteristics of concern will be stability of voltages and power flows. Steady-state and transient conditions will have to be tested. Interactions with the distribution system's protection scheme will also have to be studied.

\subsubsection{System Dynamic Stability}

New types of reliability services should be investigated and tested. For example, frequency oscillations could be sensed and the DER programmed to react to dampen the oscillation. This is becoming an increasing concern for the Western Systems Coordinating Council (WSCC). Tests are required to develop the methodology and the technology to perform this service. A test bed with an actual grid would be preferable.

\subsubsection{System Dynamic Modeling}

There is concern about how to assess the effects of DER on system stability and what changes are needed in protection schemes. Little information is currently available on the electrical parameters (e.g., time constants, reactances, transient responses) of the small machines used in distributed technologies. These parameters are needed in order to develop transient stability and system security models. These models are particularly critical because the transient responses of DER and power electronics are much faster than those of traditional machines. The characteristics of the local control systems must also be considered. We also do not know how clustering of small DG and storage affect the larger bulk power system. The industry needs to develop new models and, through testing, obtain the data to support them, including data on the loads as well as the DG and storage technologies that may be serving them. 


\subsection{CONCLUSIONS}

Test beds will be required to verify distributed generators' physical capabilities to deliver the full range of energy and ancillary services. Test bed results will help identify unit-specific and system shortcomings. Initially, the testing of the communications and aggregation schemes can be done separately from the testing of the distributed generators themselves, but integrated testing and field demonstrations will ultimately be required. It will be necessary to test various DG technologies and various electric power system configurations. Testing of multiple distributed generators operating simultaneously and in close proximity will also be required. All of this testing is not likely to be accommodated with only one or two test beds. 


\section{REFERENCES}

Alderfer, B. R., M. Eldridge, and T. J. Starrs. 2000. Making Connections - Case Studies of Interconnection Barriers and their Impact on Distributed Power Projects. NREL/SR-200-28053. Golden, Colo.: National Renewable Energy Laboratory, May. Available on-line at http://ntwebsrv3-1a.nrel.gov/dpp/barrierreport and http://www.nrel.gov/docs/ fy00osti/28053.pdf .

Battles, S. J. 1999. "Electricity Generation in the Manufacturing Sector: A Historical Perspective." Paper presented at the 20th Annual North American Conference of the United States Association for Energy Economics (affiliated with the International Association for Energy Economics), September 1. Available online at http://www.eia.doe.gov/emeu/efficiency/iaee99_final.htm

DOE (U.S. Department of Energy). 1999. Supporting Analysis for the Comprehensive Electricity Competition Act. DOE/PO-0059. Washington: D.C.: Office of Economic, Electricity and Natural Gas Analysis, U.S. Department of Energy, May.

DOE (U.S. Department of Energy). 2000. "The Use of DG to Reinforce System Reliability on the Delmarva Peninsula.” Prepared by Electrotek Concepts for the U.S. Department of Energy, Office of Power Technologies, May 23.

Kirby, B. J., and E. A. Hirst. 1999. "New Blackstart Standards Needed for Competitive Markets." IEEE Power Engineering Review 19, no. 2 (February): 9.

Kirby, B. J., and E. A. Hirst. 2000a. "Bulk-Power Reliability and Commercial Implications of Distributed Resources." National Association of Regulatory Utility Commissioners (NARUC), February 5.

Kirby, B. J., and E. A. Hirst. 2000b. Customer Specific Metrics for the Regulation and Load Following Ancillary Services. ORNL/CON-474. Oak Ridge, Tenn.: Oak Ridge National Laboratory, January.

Oregonian. 1999a. "Senate Flips the Switch on Electricity Generation." The Oregonian (Portland, Ore.), April 21.

Oregonian. 1999b. "House Passes Electricity Reform." The Oregonian, July 3. 
ORNL/TM-2001/136

\section{INTERNAL DISTRIBUTION}

\author{
15-17. J. D. Kueck \\ 18. R. M. Lee \\ 19. T. J. McIntyre \\ 20-23. C. I. Moser \\ 24. D. T. Rizy \\ 25. R. B. Shelton \\ 26-28. R. H. Staunton \\ 29. J. P. Stovall \\ 30. Central Research Library \\ 31. ORNL Laboratory Records - RC
}

\section{EXTERNAL DISTRIBUTION}

32. Lilia A. Abron, PEER Consultants, 1460 Gulf Blvd., 11th Floor, Clearwater, FL 33767

33. Douglas C. Bauer, Executive Director, Commission on Engineering and Technical Systems, National Research Council, Harris 280, 2001 Wisconsin Ave. NW, Washington, DC 20007

34. Susan L. Cutter, Professor and Chair, Department of Geography, University of South Carolina, Columbia, SC 29208

35. Deborah Haught, Office of Distributed Energy Resources, U.S. Department of Energy, EE-16, Washington, DC 20585

36. Patricia Hoffman, Office of Distributed Energy Resources, U.S. Department of Energy, EE-16, Washington, DC 20585

37. Phil Overholt, Office of Distributed Energy Resources, U.S. Department of Energy, EE-16, Washington, DC 20585

38. P. Richard Rittelmann, FAIA, Executive Vice President, Burt Hill Kosar Rittelmann Associates, 400 Morgan Center, Butler, PA 16001-5977

39. Susan F. Tierney, Economic Resource Group, Inc., One Mifflin Place, Cambridge, MA 02138

40. C. Michael Walton, Ernest H. Cockrell Centennial Chair in Engineering, Department of Civil Engineering, University of Texas at Austin, Austin, TX 78712-1076 